\title{
Disability and incapacity benefits
}

\section{The role that doctors play}

\author{
Maura Killoughery
}

In the UK the Benefits Agency is responsible for the administration and payment of Disability and Incapacity benefit, and it relies upon its Medical Services for the medical expertise needed in the assessment process. Using a Medical Services Centre serving south-east England as a model, an investigation was carried out to see how applications for disability and incapacity benefits are assessed. The purpose of this article is to provide information which will allow psychiatrists to be better informed about key existing benefits and, in particular, to give insight into the role of doctors in these decisions.

Many psychiatric patients are entitled to incapacity or disability benefits. Although the Benefit Agency attempts to exercise particular care when dealing with service users who have a mental illness, anecdotal evidence from psychiatrists and care managers suggests considerable apparent inconsistency in overall result for claimants with mental illness. These issues affect potentially all psychiatric patients in the benefit system. They may add to anxiety levels about availability of benefits (or whether benefits could be stopped) and, undoubtedly, some aspects of social deprivation (and, thus, mental illness) may be ameliorated by the extra money benefits bring. The availability of benefits to psychiatric patients, whether granted or not, may affect outcome.

\section{Benefits and the Benefits Agency}

The organisation that is responsible for the administration and payment of benefits is the Benefits Agency. Figure 1 shows the structure of the Benefits Agency. This article is concerned with three benefits: Disability Living Allowance, Severe Disablement Allowance and Incapacity Benefit (for an overview of other benefits see Which Benefit (Benefits Agency Communications and Customer Liaison Branch, 1998)).

\section{Medical services}

The Benefits Agency medical service is provided in regional centres by the SEMA group. Depending on the benefit claimed and the underlying medical grounds, a referral may then be made to a medical services centre.

Each medical services centre organises the medical administration for the above benefits and arranges for medical assessments to be carried out in designated examination centres throughout the country. For example, there are 17 examination centres in the south-east of the UK and about 14 full-time doctors employed by the SEMA group. The south-east of the UK has a population of 10-12 million people, which typically generates approximately about 15000 referrals for medical conditions every month. Of these, 7000 patients will need to be examined.

In addition to the 14 full-time doctors, 450 sessional or part-time doctors are also retained by the medical service in the south-east. Fulltime doctors are responsible for maintaining the quality of work carried out by the other medical staff. They check reports for uniformity of standards and train and supervise new staff.

Adjudication officers decide if, in law, a claimant displays the degree of disability required for the benefit claimed. They are not medically trained and come from a variety of backgrounds, including business. Full-time doctors are able to help adjudication officers by providing information about medical conditions, and in difficult cases they may make recommendations to them.

All medical staff can carry out medical examinations, and a help desk is run from each medical service centre to answer any queries raised by examining doctors, adjudication officers or benefit offices. It should be noted that the work involved in these medical assessments has a different emphasis to that in most other branches of medicine. The purpose of the assessment process is to accurately identify and describe functional abilities of the service user and is not concerned with treatment or diagnosis. Doctors who undertake this work also come from a variety of backgrounds and include general practitioners (GPs) and retired or practising physicians or psychiatrists. 


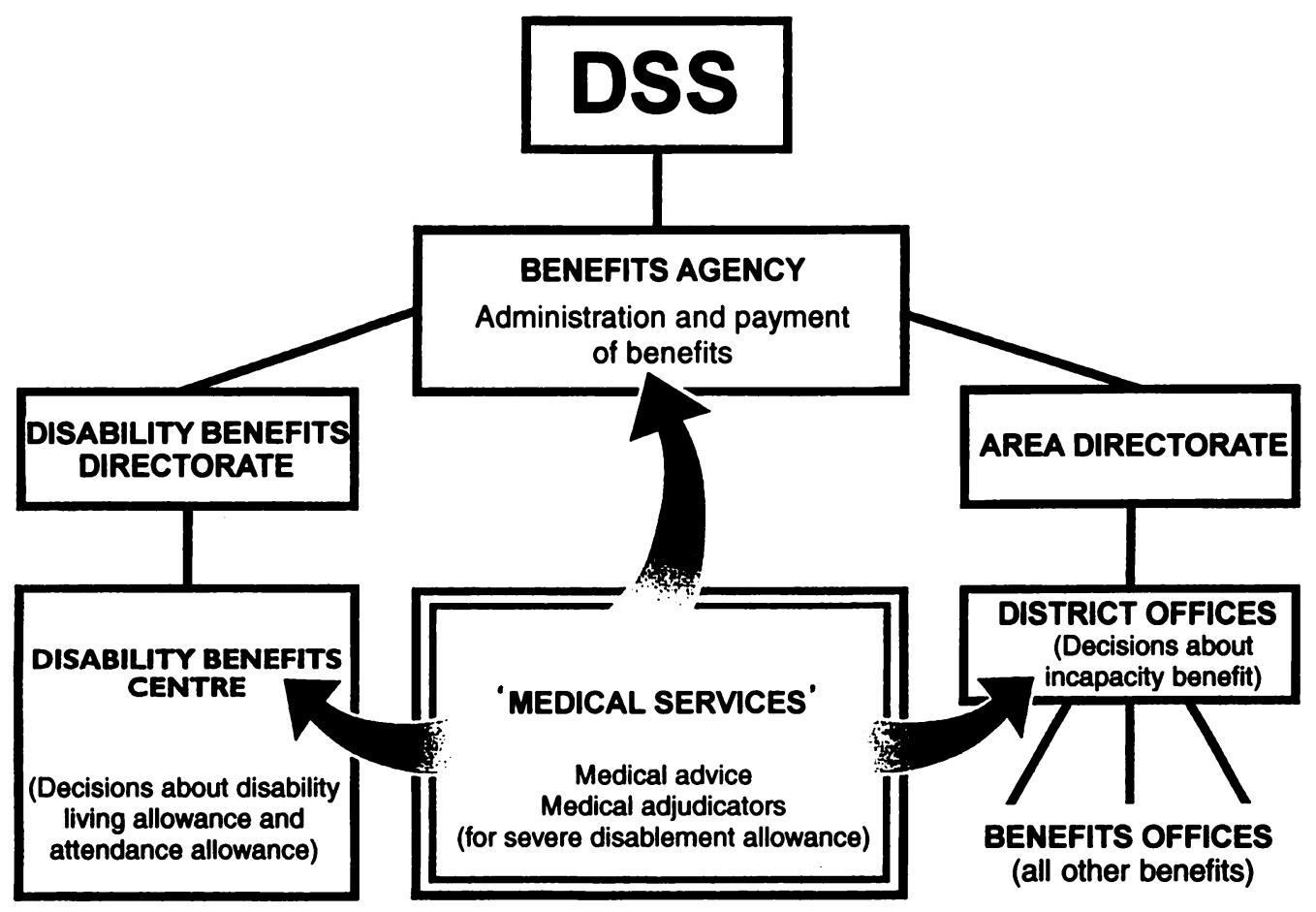

Fig. 1. The structure of the Benefits Agency

\section{Incapacity Benefit}

The current system is based on two criteria: the first is the inability of the service user to do his or her own job (Own Occupation Test); and the second is the inability to do any job (All Work Test). For the first 28 weeks of illness, benefit is awarded to an employed person if he or she is deemed to be unable to do his or her own job. The Medical Services consider what is written on the sick notes provided by the patient's GP and, in practice, Incapacity Benefit is usually granted for this period of time, provided the certificate indicates a significant illness.

After 28 weeks (or immediately if the person became incapable of work while unemployed) the All Work Test applied. At this stage, both the patient and his or her doctor is asked for further information about the patient's condition. The decision then made by the medical services is whether their doctors need to assess the patient and the written information, that is, do they need to apply the All Work Test to the patient. Patients must provide the information required by the Benefits Agency and if invited to attend for examination they are obliged to do so. However, no individual is disallowed benefit without an offer of a medical assessment.

\section{Severe mental illness exemption}

Some conditions are automatically exempt from the All Work Test. In addition to physical complaints these include severe mental illness, dementia and severe learning disability. In these cases Incapacity Benefit is automatically granted.

Although there is no standard definition of 'severe mental illness', there are a number of accepted guidelines. If the patient attends a NHS day hospital, if they are psychiatric inpatients, or if they are unable to maintain reasonable social interaction, they are usually exempt from the All Work Test. The exact criteria are flexible and may include a combination of factors such as the medication the patient is taking and the circumstances; for example, a suicidal patient on antidepressants may be exempt for a limited period. In practice. 
patients with severe depression, psychosis or severe neurosis, such as obsessive-compulsive disorder, are usually classified as severely mentally ill. These patients are usually identified by the information given by their own doctor (and the patient is not asked to complete a questionnaire). Information on diagnosis and incapacity for work may be obtained via the GP or from information contained in a psychiatric report. Patients with drug or alcohol misuse are not normally exempt from the All Work Test.

\section{Medical examination}

For those without a clear assessment of sufficient incapacity on medical or psychiatric grounds a medical examination is necessary. An assessment carried out by a Benefits Agency doctor will look at overall functional ability, specific functions and special senses. An important part of the examination will be to look at the doctor's numerical description of functional capacity (this is called a descriptor) and to compare it with that used by the patient. If a difference is found, the doctor's explanation of any discrepancy is usually accepted.

For those patients with mental illness the All Work Test also includes a Mental Health Test, which looks to assess four main areas of mental function. Specifically these are - completion of tasks, daily living, coping with pressure and interaction with other people.

When a claim is successful and Incapacity Benefit is granted, it may be time-limited or it may be granted indefinitely. 'Therapeutic work' may still be carried out by a claimant provided it is for less than 16 hours per week and it is subject to an earnings limit of $£ 44.00$ (after expenses) without loss of benefit. This rule does not apply to claimants whose work is in hospital institutions or sheltered workshops.

\section{Disability Living Allowance}

Disability Living Allowance may be awarded for people who need help with either of two areas of life - personal care or mobility. The care component of Disability Living Allowance covers two areas. The first is for those people who need help with things such as washing, dressing and using the toilet (for example, some psychiatric patients who are in danger of self-neglect). The second is for people who need supervision to avoid substantial danger to themselves. Patients who might be covered by the supervision description include those with learning disability, epilepsy, a major depressive disorder with suicidal ideation and psychotic illness if there is a risk to self or others.

The care component is awarded at three rates; the highest when 24-hour care is needed. (for example, severe dementia) the middle rate when attention during the day or night is needed and the lowest rate when assistance is needed to plan or prepare the daily main meal (as, for example, in a patient with chronic schizophrenia in whom negative symptoms are predominant).

The mobility component of the Disability Living Allowance is awarded at two levels. The higher level is awarded to claimants who are unable to walk, while the lower level is for those who, although capable of walking, cannot walk safely in areas that are unknown to them. This later condition could be applied to some patients with psychosis. The Benefits Agency medical service's doctors complete the medical report form for Disability Living Allowance after a medical examination has been carried out. As assessment of ability to prepare food, mental competence, tendency to wander and where there are episodes of altered awareness is part of this process.

\section{Severe Disablement Allowance}

Severe Disablement Allowance is assessed in the same way as Incapacity Benefit, but in this case the claimant will not have paid enough National Insurance Contributions to recelve Incapacity Benefit. The claimant must not have been able to work for 28 weeks because of illness or disablement and be at least $80 \%$ disabled.

\section{Appeals process}

For patients who wish to appeal against their benefits assessment there is an independent tribunal service (separate from the Department of Social Security). These tribunals all have at least one medical assessor (who can interpret medical evidence or describe how an illness can cause disability), a lay member and a legal chairperson. Incapacity Benefit appeals, for example, are dealt with by the Social Security Appeals Tribunal, while Severe Disablement Allowance is dealt with by the Disability Appeals Tribunal. The appeals tribunal's decision is final and there is no comeback for the Benefits Agency once a decision has been reached. Claimants may attend the hearing and it is thought to be in their favour if they do.

The appeals process usually takes between three and eight months to complete. For Incapacity Benefit, $50 \%$ of claimants who complete the All Work Test are not awarded benefit and $30 \%$ of these appeal. Approximately $60-70 \%$ of appeals are upheld. 


\section{Guidelines for psychiatrists}

For those patients who wish to claim benefit, in virtually all cases, it is in their best interests to have a care manager or preferably someone from the Citizens' Advice Bureau to help them fill in the appropriate forms. Current forms are very much geared towards physical rather than mental illness and considerable care is required in filling them in to interpret each question as relates to mental health. Factors that would otherwise be overlooked, highlighting how the illness impacts on everyday life, can then be addressed. As a general rule not enough information is put on forms and if it is difficult to convey the way in which a patient's psychiatric difficulties are disabling, a supporting letter from the psychiatrist can be very helpful. Such a letter should give a short history of the illness, diagnosis, details of treatment and compliance with medication. It is helpful to cover insight, future management and details of how the illness affects everyday life, and, if appropriate, describe the role that any carer might have.

\section{Comment}

There are changes afoot within the Benefits Agency (the privatisation of the services is a recent move) as well as to benefits. The Social Security Act 1998 received Royal Assent this year, and it is likely to change the way in which decisions about state benefits are made. The last major changes to the benefits system in 1992 reduced the steeply rising cost of sickness benefits by changing the 'gatekeeper' from the GP to Benefits Agency staff after 28 weeks. This change alone resulted in a large drop in the annual cost of sickness benefits. In the current climate, the government of the day will always be keen to reduce the annual cost of benefits, but the critical task will be to see if changes can also be made which will improve patients' quality of life.

\section{Acknowledgements}

With thanks to the Medical Services Centre in Sutton and the Disability Rights Project in Richmond, for their help.

\section{Reference}

BENEFTTS AGENCY COMmunications and Customer liaison Branch (1998) Which Benefit. London: The Stationery Office.

Maura Killoughery, Specialist Registrar, Richmond Community Health Resource Centre, Richmond Royal, Kew Foot Road, Richmond TW9 2TE 